\title{
ANALYSIS OF PHYSICS LEARNING MATTER INTEGRATED DISASTER IN WEST SUMATERA
}

\author{
Muhammad Arif ${ }^{* 11}$, Dina Syaflita ${ }^{2)}$ \\ ${ }^{1)}$ Pendidikan Geografi, STKIP Pesisir Selatan \\ ${ }^{2)}$ Pendidikan Fisika, Universitas Riau \\ e-mail: muhammadarif838@gmail.com \\ dinasyaflita@ayahoo.com
}

\begin{abstract}
West Sumatera is a disaster prone area, especially disasters such as earthquakes, landslides, floods, tsunamis, and volcanoes. The high potential of natural disasters has consequences for the importance of disaster mitigation efforts. School is an effective tool in shaping of mindset and behavior of students. One effort that can be done is integrate the topic of natural disaster into learning, especially physics learning. Integrating physical matter in learning requires material analysis aimed at making disaster topics integrated in accordance with learning topic. The type of this research is descriptive research. The results of the research indicate that an analysis of the relevance of learning material to the topic of integrated disasters needs to be done so that the integration between teaching material and the topic of disasters is carried out in harmony. Almost all physics learning material can be integrated with the topic of disasters that often hit the West Sumatra region. The classification of material on the topic of integrated disasters is classified into fact and metacognitive material.
\end{abstract}

Keywords:integrated physic, mitigation, natural disaster

\section{ANALISIS MATERI PEMBELAJARAN FISIKA TERINTEGRASI BENCANA ALAM DI SUMATERA BARAT}

\author{
Muhammad Arif ${ }^{* 11}$, Dina Syaflita ${ }^{2)}$ \\ ${ }^{1)}$ Pendidikan Geografi, STKIP Pesisir Selatan \\ ${ }^{2)}$ Pendidikan Fisika, Universitas Riau
}

\begin{abstract}
Abstrak
Sumatera barat merupakan daerah rawan bencana terutama bencana seperti gempa bumi, tanah longsor, banjir, tsunami, dan gunung meletus. Tingginya potensi bencana alam ini memberikan konsekuensi pentingnya upaya mitigasi bencana. Sekolah merupakan sarana yang efektif dalam membentuk pola pikir dan prilaku peserta didik. Salah satu upaya yang dapat dilakukan adalah mengintegrasikan topik bencana alam kedalam pembelajaran, terutama pembelajaran fisika. Pengintegrasian materi fisika dalam pembelajaran membutuhkan analisis materi yang bertujuan agar topik bencana yang diintegrasikan sesuai dengan materi ajar. Jenis penelitian ini adalah penelitian deskriptif. Penelitian ini merupakan salah satu kategori penelitian kualitatif. Analisis materi dilakukan pada silabus Fisika kelas XI semester 1. Hasil penelitian menunjukkan bahwa analisis keterkaitan materi ajar dengan topik bencana yang diintegrasikan perlu dilakukan agar pengintegrasian antara materi ajar dengan topik bencana dilakukan secara harmonis. Hampir semua materi pembelajaran fisika dapat diintegrasikan dengan topik bencana yang sering melanda wilayah Sumatera Barat. Klasifikasi materi pada topik bencana yang diintegrasi digolongkan dalam materi fakta dan metakognitif.
\end{abstract}

Kata kunci: bencana alam, fisika terintegrasi, mitigasi 


\section{Pendahuluan}

Sumatera Barat merupakan salah satu Provinsi yang rawan bencana alam. Kondisi geografis wilayah Sumatera Barat dengan topografi yang bervariasi menyebabkan wilayah ini menjadi wilayah rawan bencana. Perda Provinsi Sumatera Barat Nomor 5 Tahun 2007 tentang penanggulangan bencana menyatakan bahwa Sumatera Barat merupakan daerah rawan bencana terutama bencana alam seperti gempa bumi, tanah longsor, banjir, tsunami, dan gunung Meletus (Perda, 2007).

Tingginya potensi bencana alam di Sumatera Barat membawa konsekuensi pentingnya upaya mitigasi bencana untuk mengurangi dampak resiko dari bencana. Kondisi gawat darurat akibat bencana alam membutuhkan kesiapan individu dimanapun dan kapanpun dalam menghadapi bahaya yang datang dari lingkungannya sendiri (Malahika, et al., 2016). Salah satu upaya mitigasi bencana alam adalah melalui pembelajaran dan pendidikan (Sasikome, et al., 2015).

Pengetahuan mengenai bencana perlu ditanamkan sejak dini agar peserta didik dapat mengetahui perbuatan yang merusak alam dan perbuatan yang dapat mencegah bencana alam (Setiawati, et al., 2013). Pengetahuan tentang bencana dan mitigasinya kepada peserta didik penting dilakukan agar peserta didik sedini mungkin memperoleh pengetahuan terkait bencana yang sering melanda daerahnya sehingga menghasilkan peserta didik yang tanggap dan siaga bencana.

Pendidikan memberikan kontribusi berarti dalam pembentukan karakter peserta didik dalam menghadapi bencana (Sasikome, et al., 2015). Pendidikan berperan penting untuk membangun sebuah budaya keselamatan dan ketangguhan disemua tingkat. Sekolah sebagai media informasi diharapkan dapat menjadi perpanjangan tangan pemerintah dalam memberikan informasi penting terkait bencana kepada peserta didik sebagai upaya mitigasi. Sekolah merupakan sarana yang efektif dalam membentuk pola pikir dan pola prilaku anak. Untuk itu, dalam rangka mendukung program pemerintah untuk mengurangi resiko bencana sekolah perlu mengintegrasikan informasi kebencanaan baik melalui kurikulum maupun budaya keselamatan sekolah (Astuti, et al.,
2010). Salah satu pembentukan sikap yang dapat dibentuk adalah sikap siaga bencana.

Pemberian pengetahuan terkait bencana melalui kurikulum dapat dilakukan dengan mengintegrasikan materi bencana ke dalam pembelajaran. Fisika merupakan mata pelajara yang erat kaitannya dengan kebencanaan. Fisika merupakan disiplin ilmu alam yang mengaji masalah fenomena-fenomena alam, salah satunya adalah bencana alam. Fenomena bencana alam dapat diintegrasikan ke dalam beberapa materi Fisika. Fisika merupakan bagian Ilmu Pengetahuan Alam (IPA) yang membangun dan mengorganisasikan pengetahuan dalam bentuk penjelasan yang dapat diuji dan mampu memprediksi fenomena alam yang berhubungan dengan prilaku dan struktur benda. Kegiatan pembelajaran yang mengaji masalah fenomena alam membutuhkan perangkat pembelajaran yang mendukung. Oleh karena fisika mengkaji masalah fenomena alam, maka setiap sub materi dapat terintegrasi dengan materi bencana alam.

Pengintegrasian materi fisika dalam pembelajaran membutuhkan analisis materi yang bertujuan agar topik bencana yang dikemukakan sesuai dengan materi ajar yang akan dipelajari. Analisis materi menempati posisi yang sangat penting agar pelaksanaan pembelajaran dapat mencapai sasaran. Istilah fakta, konsep, prosedur, dan metakognitif pada materi pembelajaran menurut Permendikbud Nomor 20 Tahun 2016 (Permendikbud, 2016). Penjelasan dari istilah-istilah yang telah disebutkan dijabarkan dalam Tabel 1.

Pembelajaran fisika di wilayah Sumatera Barat perlu mengintegrasikan pengetahuan bencana alam kedalam materi ajar. Hal ini disebabkan karena Sumatera Barat merupakan wilayah rawan bencana, maka perlu diberikan pengetahuan mengenai bencana dan mitigasinya kepada peserta didik. Selain itu, fisika merupakan mata pelajaran yang berhubungan dengan fenomena alam. Bencana alam merupakan salah satu fenomena yang penting diintegrasikan ke dalam materi pembelajaran fisika. Adapun tujuan penulisan artikel ini adalah untuk menganalisis materi fisika dengan topik bencana alam yang dapat diintegrasikan. 
Tabel 1. Penjelasan fakta, konsep, prosedur, dan metakognitif

\begin{tabular}{|c|c|c|}
\hline No & Kategori & Keterangan \\
\hline 1 & Fakta & $\begin{array}{l}\text { Pengetahuan teknis dan } \\
\text { spesifik, detail dan kom- } \\
\text { pleks berkenaan dengan } \\
\text { ilmu pengetahuan, tek- } \\
\text { nologi, seni, dan budaya. }\end{array}$ \\
\hline 2 & Konsep & $\begin{array}{l}\text { Terminologi/istilah dan } \\
\text { klasifikasi, kategori, prin- } \\
\text { sip, generalisasi, teori, } \\
\text { model, dan struktur yang } \\
\text { digunakan terkait dengan } \\
\text { pengetahuan teknis dan } \\
\text { spesifik, detail dan } \\
\text { kompleks. }\end{array}$ \\
\hline 3 & Prosedur & $\begin{array}{l}\text { Pengetahuan tentang cara } \\
\text { melakukan sesuatu atau } \\
\text { kegiatan yang terkait } \\
\text { dengan pengetahuan tek- } \\
\text { nis, spesifik, algoritma, } \\
\text { metode, dan kriteria untuk } \\
\text { menentukan prosedur } \\
\text { yang sesuai berkenaan } \\
\text { dengan ilmu pengetahuan, } \\
\text { teknologi, seni, dan } \\
\text { budaya. }\end{array}$ \\
\hline 4 & $\begin{array}{l}\text { Meta- } \\
\text { kognitif }\end{array}$ & $\begin{array}{l}\text { Pengetahuan tentang } \\
\text { kekuatan dan kelemahan } \\
\text { diri sendiri dan meng- } \\
\text { gunakannya dalam mem- } \\
\text { pelajari pengetahuan tek- } \\
\text { nis, detail, spesifik, } \\
\text { kompleks, kontekstual } \\
\text { dan kondisional. }\end{array}$ \\
\hline
\end{tabular}

Sumber: (Permendikbud, 2016).

\section{Bahan dan Metode}

Jenis penelitian ini adalah penelitian deskriptif. Penelitian ini merupakan kategori penelitian kualitatif, yang berupaya untuk memperoleh deskripsi yang mendetail tentang topik-topik bencana yang sesuai dengan jenis materi fisika tertentu. Analisis materi dilakukan pada silabus fisika SMA kelas XI semester I.

Jenis data yang digunakan dalam penelitian ini adalah data primer. Instrumen yang digunakan dalam penelitian ini adalah lembar analisis materi pembelajaran fisika. Teknik analisis data yang digunakan adalah analisis deskriptif mengenai keterkaitan materi pembelajaran fisika dengan topik bencana yang sesuai. Data yang diperoleh dijabarkan dalam bentuk tabel.

\section{Hasil dan Pembahasan}

Analisis materi sangat perlu dilakukan. Analisis keterkaitan materi ajar dengan topik kebencanaan bertujuan untuk menentukan jenis bencana yang sesuai dengan materi ajar, menentukan jenis kategori topik bencana ke dalam fakta, konsep, prosedur, metakognitif, dan menyusun bahan ajar sehingga integrasi topik bencana ke dalam materi ajar dapat dilakukan dengan baik. Hal ini sesuai dengan pendapat Mulyatiningsih (2016) yaitu analisis materi bertujuan untuk mengidentifikasi materi utama, memilih materi yang relevan, dan menyusunnya kembali secaara sistematis. Menurut Rusilowati, et al., (2015), pemetaan mata pelajaran dan materi ajar dilakukan agar pembelajaran terintegrasi bencana alam dan kearifan lokal dapat dilaksanakan secara harmonis, tidak tumpang tindih atau kelebihan muatan.

Beberapa strategi integrasi pendidikan kebencanaan yang dapat dilakukan adalah melalui pengamatan langsung, menggunakan media pembelajaran, dan bahan ajar berupa LKS (Septikasari \& Ayriza, 2016). Media pembelajaran dan bahan ajar membutuhkan kegiatan analisis materi pembelajaran. Analisis materi yang baik berdampak pada bahan ajar terintegrasi bencana yang dihasilkan. Apabila analisis materi dilakukan dengan baik, maka bahan ajar yang dihasilkan berisi materi ajar yang terintegrasi secara harmonis dengan topik bencana.

Bencana alam yang sering melanda wilayah Sumatera Barat adalah gempa bumi, tanah longsor, banjir, tsunami, dan gunung Meletus (Perda, 2007). Diperlukan analisis materi untuk mencocokkan keterkaitan antara materi ajar dengan topik bencana yang diberikan dalam pembelajaran. Hasil analisis keterkaitan materi Fisika kelas XI dengan topik kebencanaan di Sumatera Barat ditampilkan dalam Tabel 2. 
Tabel 2. Analisis keterkaitan materi ajar dengan topik bencana yang diintegrasikan

\begin{tabular}{|c|c|}
\hline No & Materi Pokok \\
\hline 1 & $\begin{array}{l}\text { Analisis vektor untuk, gerak } \\
\text { parabola dan gerak } \\
\text { melingkar } \\
\text { - Posisi, kecepatan, dan } \\
\text { percepatan gerak dua } \\
\text { dimensi (gerak lurus } \\
\text { dan gerak parabola) } \\
\text { - Posisi, kecepatan, dan } \\
\text { percepatan gerak } \\
\text { melingkar }\end{array}$ \\
\hline 2 & $\begin{array}{l}\text { Hukum Newton tentang } \\
\text { Gravitasi } \\
\text { - gaya gravitasi antar } \\
\text { partikel } \\
\text { - kuat medan gravitasi } \\
\text { dan percepatan gravitasi } \\
\text { - hukum Kepler }\end{array}$ \\
\hline
\end{tabular}

\section{Tanah Longsor:}

Materi tanah longsor dapat diintegrasikan dengan materi gerak pada analisis pergeseran atau perpindahan massa.

\section{Gunung Meletus:}

Jenis gerak yang terdapat pada lontaran material gunung meletus dapat dikategorikan sebagai jenis gerak parabola. Integrasi topik bencana ini dapat dilakukan pada kegiatan mengamati dalam kegiatan saintifik melalui tampilan visual maupun dalam tahap pengayaan dan wacana soal.

Untuk materi ini topik kebencanaan yang ada di Sumatera Barat kurang cocok dikaitkan dengan materi ini. Kemungkinan dapat digunakan topik kejatuhan meteor, namun bencana ini tidak termasuk bencana yang sering melanda Sumatera Barat.
3 Usaha dan energi

- Energi kinetik dan energi potensial (gravitasi dan pegas)

- Konsep usaha

- Hubungan usaha dan energi kinetik

- Hubungan usaha dengan energi potensial

- Hukum kekekalan energi mekanik

\footnotetext{
Tanah Longsor:

Dalam pembelajaran konversi energi, materi tanah longsor dapat digunakan dimana material yang semula hanya memiliki energi potensial berubah menjadi energi dalam bentuk lain.
}

\section{Banjir:}

Air yang meluap dan bergerak dengan kecepatan tertentu memiliki sejumlah energi kinetik. Semakin cepat laju fluida semakin tinggi kecepatannya. Buktinya, semakin cepat laju fluida semakin besar kerusakan yang disebabkannya.

Integrasi banjir dapat dilakukan dalam tahap pengamatan maupun pengayaan.

\section{Gempa Bumi:}

Materi gempa bumi dalam hal energi dapat diberikan dalam bentuk konfirmasi dan penguatan oleh pendidik atau dalam bentuk pengayaan.

\section{Tsunami:}

Gelombang laut yang sangat besar membawa energi yang juga sangat besar. Pada tsunami, konversi energi yang terjadi dapat berhubungan dengan bencana yang lain seperti gempa bumi. Bencana tsunami dalam materi usaha dan energi paling baik diberikan dalam bentuk pengayaan.

\section{Gunung Meletus:}

Perubahan energi yang ditimbulkan oleh lontaran material dari dalam perut bumi dapat dijadikan contoh hubungan antara usaha dan energi. 


\begin{tabular}{|c|c|c|}
\hline No & Materi Pokok & Topik Bencana yang sesuai \\
\hline 4 & $\begin{array}{l}\text { Getaran Harmonis } \\
\text { - Karakteristik getaran } \\
\text { harmonis (simpangan, } \\
\text { kecepatan, percepatan, } \\
\text { dan gaya pemulih) pada } \\
\text { ayunan bandul dan } \\
\text { getaran pegas } \\
\text { - Persamaan simpangan, } \\
\text { kecepatan, dan } \\
\text { percepatan }\end{array}$ & $\begin{array}{l}\text { Gempa Bumi: } \\
\text { Meskipun pada kenyataannya gempa bumi bukanlah contoh } \\
\text { getaran harmonis, dalam paling tidak dapat dijadikan sebagai } \\
\text { contoh getaran yang pernah dirasakan dalam kehidupan sehari- } \\
\text { hari. }\end{array}$ \\
\hline 5 & $\begin{array}{l}\text { Momentum, impuls, dan } \\
\text { tumbukan }\end{array}$ & $\begin{array}{l}\text { Secara umum, hampir semua topik dapat diintegrasikan dengan } \\
\text { materi momentum, impuls, dan tumbukan. Misalnya tanah } \\
\text { longsor menghantam rumah penduduk (bias berupa lenting } \\
\text { sebagian maupun tidak lenting), tumbukan akibat lontaran } \\
\text { material gunung meletus, tumbukan lempeng bumi pada topik } \\
\text { bencana gempa bumi, hantaman banjir dan tsunami pada } \\
\text { rumah-rumah maupun infrastruktur. Pengintegrasian materi } \\
\text { momentum, impuls, dan tumbukan dengan topik bencana } \\
\text { paling baik dalam kegiatan pengayaan. }\end{array}$ \\
\hline
\end{tabular}

Berdasarkan Tabel 2. menunjukkan bahwa hampir semua materi pembelajaran dapat dikaitkan dengan topik kebencanaan. Pemilihan topik kebencanaan yang akan diintegrasikan dengan materi bergantung pada materi yang diajarkan. Dalam keempat klasifikasi materi yang dijelaskan oleh Tabel 1, maka bencana alam yang diintegrasikan dengan materi ajar digolongkan ke dalam jenis fakta dan metakognitif. Fakta dimana semua topik bencana merupakan kejadian nyata dan dapat dirasakan dan dilihat langsung oleh peserta didik. Metakognitif dimana peserta didik dapat menilai sendiri secara kondisional pengetahuan kebencanaan dan kemampuan mitigasi yang dimiliki. Umumnya, pengetahuan kebencanaan berupa fakta dapat ditampilkan dalam tahap mengamati pada langkah kegiatan saintifk. Selain itu, juga dapat digunakan guru dalam memberikan konfirmasi dan penguatan kepada peserta didik dalam bentuk informasi kebencanaan secara kontekstual. Keterkaitan topik bencana juga dapat diberikan dalam tahap pengayaan.

Penelitian yang dilakukan oleh Rusilowati, et al., (2015) menghasilkan analisis materi Fisika dengan topik kebencanaan dan mitigasinya pada materi gelombang, getaran, dan gerak. Penelitian ini mengaitkan materi gelombang dengan bencana tsunami, getaran dengan gempa, dan gerak dengan tanah longsor. Penelitian ini sesuai dengan hasil penelitian pada Tabel 2.

Pada Tabel 2, hasil kajian mengaitkan materi getaran dengan gempa bumi. Meskipun gempa bukan contoh getaran sederhana, tetapi materi gempa dapat digunakan sebagai fakta dalam pembelajaran yang dapat dirasakan langsung oleh peserta didik. Melalui penyampaian fakta ini, pendidik dapat melanjutkan pembelajaran kepada mitigasi bencana gempa. Materi analisis vektor yang berisi pembelajaran tentang analisis gerak lurus dan gerak parabola dapat diintegrasikan dengan bencana tanah longsor dan gunung meletus. Analisis gerak lurus mengenai perpindahan benda dapat dikaitkan dengan perpindahan massa tanah longsor selain itu juga dapat dikaitkan dengan gerak lontaran material gunung meletus. Lontaran material gunung meletus juga dapat dikaitkan dengan materi gerak parabola.

\section{Kesimpulan dan Saran}

Analisis keterkaitan materi ajar dengan topik bencana yang diintegrasikan memberikan kesimpulan bahwa analisis ini perlu dilakukan 
agar pengintegrasian antara materi ajar dengan topik bencana dilakukan secara harmonis. Hampir semua materi pembelajaran fisika dapat diintegrasikan dengan topik bencana yang sering melanda wilayah Sumatera Barat. Klasifikasi materi pada topik bencana yang diintegrasi digolongkan dalam materi fakta dan metakognitif.

Penelitian ini menganalisis keterkaitan topik bencana alam di Sumatera Barat dengan materi pelajaran kelas XI semester I Kurikulum 2013 revisi. Penelitian selanjutnya dapat dilakukan untuk kelas XI semester II atau kelas $\mathrm{X}$ maupun XII. Keterkaitan materi dapat disesuaikan dengan bencana yang sering terjadi di wilayah penelitian.

\section{Daftar Pustaka}

Astuti, Siti Irene \& Sudaryomo, 2010. Peran Sekolah dalam Pembelajaran Mitigasi Bencana: Jurnal Dialog Penanggulangan Bencana, 1 (1), 30-42.

Dodon, 2013. Indikator dan Perilaku Kesiapsiagaan Masyarakat di Pemukiman Padat Penduduk dalam Antisipasi Berbagai Fase Bencana Banjir: Jurnal Perencanaan Wilayah dan Kota, 24 (2), 125-140.

Malahika, Masita, Sefty Rompas, \& Jeavery Bawotong, 2016. Pengaruh Penyuluhan Kesiapsiagaan Bencana Banjir terhadap Pengetahuan Keluarga di Lingkungan I Kelurahan Pakowa Kecamatan Wanea kota Manado. Ejournal Keperawatan (eKp), 4 (2), 1-7.
Mulyatiningsih, Endang, 2016. Pengembangan Model Pembelajaran. Diakses dari http://staff. uny. ac. id/sites/default/files/ pengabdian/dra-endang-mulyatiningsih$\mathrm{mpd} / 7$ cpengembangan-modelpembelajaran. pdf. pada September.

Perda, 20107. Peraturan Daerah Provinsi Sumatera Barat Nomor 5 Tahun 2007 tentang Penanggulangan Bencana.

Permendikbud, 2016. Tentang Standar Kompetensi Lulusan Pendidikan Dasar dan Menengah, Permendikbud Nomor 20 Tahun 2016

Rusilowati, A., Supriyadi, S., \& Widiyatmoko, A., 2015. Pembelajaran Kebencanaan Alam Bervisi SETS Terintegrasi dalam Mata Pelajaran Fisika Berbasis Kearifan Lokal. Jurnal Pendidikan Fisika Indonesia, 1 (1), 42-48.

Sasikome, Jacklin Rifka, 2015. Pengaruh Penyuluhan Bencana Banjir terhadap Kesiapsiagaan Siswa SMP Katolik Soegiyo Pranoto Manado Menghadapi Banjir, ejournal keperawatan (e-Kp). 3 (2), 1-8.

Septikasari, Z., \& Ayriza, Y., 2018. Strategi Integrasi Pendidikan Kebencanaan dalam Optimalisasi Ketahanan Masyarakat Menghadapi Bencana Erupsi Gunung Merapi. Jurnal Ketahanan Nasional, 24 (1), 47-59.

Setiawati, I. K., \& Rusilowati, A., 2013. Pembuatan Buku Cerita IPA yang Mengintegrasikan Materi Kebencanaan Alam untuk Meningkatkan Literasi Membaca dan Pembentukan Karakter. Jurnal Pendidikan IPA Indonesia, 2 (2), 129-135. 